\title{
Numerical And Experimental Characterization Of The Transmission loss Of Complex Composite Panels
}

\author{
Maxime Bolduc, Raymond Panneton, Noureddine Atalla and Jean-Luc Wojtowicki \\ Groupe d'acoustique de l'Université de Sherbrooke, Université de Sherbrooke, Sherbrooke, Québec, J1K 2R1, Canada.
}

\section{INTRODUCTION}

The noise reduction in aircraft is now one of the top priorities for the aerospace industry, the passengers, and the crew members. Until now, many numerical studies (FEM/BEM) were conducted to predict the sound pressure levels inside the fuselage, but the size of the problem is so big that only the interior problem was taken into account.

Moreover, to be able to predict the acoustical behavior of an entire fuselage, it is a necessary to consider the exterior problem as well as the interior problem, without ignoring the fluid-structure interaction. A method to partly achieve this is to characterize the vibroacoustic behavior of the different panels from which the fuselage is made of. In order to do this, it is necessary to start with a fine validation of the numerical procedure on simpler structures such as plates and double plates systems.

In this paper, a numerical method is used and compared with experimental measurements to show its ability to finely predict the sound transmission loss of simple and complex composite panels. The studied configurations are: a simple plate, an air-filled double plate, and a double plate with cavity absorption. First, a review of the numerical modeling is presented. Second, the experimental setup is discussed. Finally, numerical and experimental results are compared.

\section{NUMERICAL CALCULATIONS}

The numerical calculations are achieved using both the finite element method (FEM) and the boundary element method (BEM). The calculations are done using an in-house software Nova. The transmission loss is obtained with [4]:

$$
T L=10 \log \frac{W_{I}}{W_{T}}
$$

Where $W_{I}$ is the incident power and $W_{T}$ is the radiated transmitted power.

\section{a) The simple plate}

For the simple plate system, application of the coupled finite and boundary element discretization procedure yields the following matrix system $[2,4]$ :

$$
\left.\left.[K]+j \varpi[Z]-\varpi^{2}[M]\right] u\right\}=\{F\}
$$

where $[\mathrm{K}]$ is the stiffness matrix, $[\mathrm{Z}]$ the radiation impedance matrix, and $[\mathrm{M}]$ the mass matrix. The vector $\{\mathrm{u}\}$ contains the nodal displacement of the meshed plate. Finally, the force vector $\{F\}$ is essentially a pressure force generated by a diffuse sound field in the emission domain.

\section{b) The double plate}

For the double plate system, the fluid in the cavity is coupled to the plates. Hence, each plate, modeled using (2), is coupled to the finite element formulation of the air cavity through a coupling matrix $\left[\mathrm{C}_{\mathrm{i}}\right]$. The global FEM/BEM matrix system is then $[2,4]$ :

$$
\left[\begin{array}{ccc}
{\left[K_{1}+j \omega Z_{1}-\omega^{2} M_{1}\right]-\left[C_{1}\right]} & 0 \\
-\left[C_{1}\right]^{T} & \frac{H}{\omega^{2}}-Q & {\left[C_{2}\right]} \\
0 & {\left[C_{2}\right]^{T}} & {\left[K_{2}+j \omega Z_{2}-\omega^{2} M_{2}\right]}
\end{array}\right]\left\{\begin{array}{c}
U_{1} \\
P \\
U_{2}
\end{array}\right\}=\left\{\begin{array}{c}
F \\
0 \\
0
\end{array}\right\}
$$

\section{c) The double plate system with porous material}

The finite element model for the porous material is based on the Johnson-Champoux-Allard model [3,5]. The physical properties of the porous material were measured using GAUS facilities for poroelastic material characterization and are given in table 1 .

Table 1 : Physical property for the equivalent fluid

\begin{tabular}{|c|c|}
\hline Property & 0.9479 \\
\hline Porosity & 3.83 \\
\hline Tortuosity & $42097.89 \mathrm{Ns} / \mathrm{m}^{4}$ \\
\hline Resistivity & $139.9^{\mathrm{E}}-6 \mathrm{~m}$. \\
\hline Caracteristic thernal lenght & $66.37^{\mathrm{E}}-6 \mathrm{~m}$. \\
\hline Caracteristic viscous lenght &
\end{tabular}

\section{EXPERIMENTAL SETUP}

The experimental setup is a coupled anechoic-reverberant room. The diffuse sound field is generated using 2 sources. The studied structure is mounted on a very stiff and massive frame fixed on the middle wall. The boundary conditions of the plates are considered clamped. The incident power is measured with 4 microphones distributed in the reverberant room and the reverberation times are measured using a $2133 \mathrm{~B} \& \mathrm{~K}$ analyzer. The transmitted radiated power is measured with a sound intensity probe. The intensity measurement is done by sweeping the entire surface of the plate facing the anechoic chamber.

\section{RESULTS}

The sound transmission loss results presented here are obtained for rectangular plates of $0.93-\mathrm{m} \times 0.5-\mathrm{m}$ wide and $4.67-\mathrm{mm}$ thick. Clamped boundary conditions are used. Figure 1 shows the numerical and experimental results obtained for the simple plate. Figure 2 shows the same results for the air-filled double plate system, while figure 3 is for the double plate with porous material. Figure 4 demonstrates the evolution of the transmission loss of the differ- 
ent structures. It shows that the porous material increases considerably the sound transmission loss of the double plate system..

\section{CONCLUSIONS}

We found for all three systems good agreement between the simulations and the experiments in the range between 20 to $1000 \mathrm{~Hz}$. The ability of the numerical method to predict correctly the low frequency acoustic behavior of finite size simple structures has been shown..

\section{ACKNOWLEDGEMENTS}

The authors wish to thank Bombardier Aerospace for its financial support and valuable discussions. Also special thanks to Youssef Atalla (Ph.D. student) for the characterization of the porous material, and to Guy Rouleau (work term student) for its help in the transmission loss measurement.

\section{REFERENCES}

[1] ALLARD, J.F. Propagation of sound in porous media: modeling sound absorbing materials. Elsevier applied science, New York, 1994.

[2] ATALLA, N. Méthodes numériques en interaction fluidestructure. Notes du cours GMC-722, Maîtrise en génie mécanique, été 1999.

[3] Champoux, Y. Étude expérimentale du comportement acoustique des matériaux poreux à structure rigide. Ph.D. thesis, Univ. Carleton, Canada, 1991.

[4]: LESUEUR, C. Rayonnement acoustique des structures. Collection Département Etudes et Recherches EDF, Eyrolles, France 1988.

[5] PANNETON, R. Modélisation numérique 3D par éléments finis des matériaux poroélastiques. Ph.D. thesis, Univ. Sherbrooke, Canada, 1996.

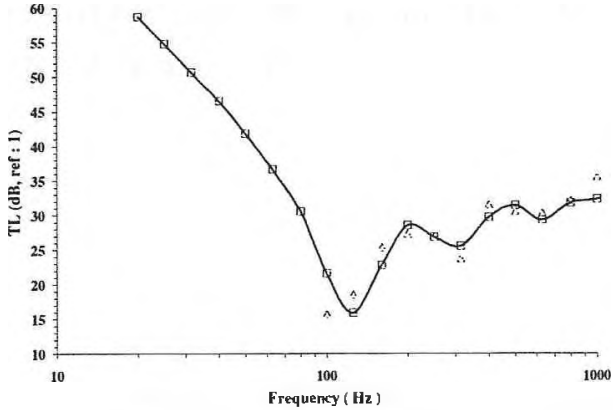

Figure 1 : Transmission loss of the simple plate. Numerical $?$ ) and experimental $(?$ )

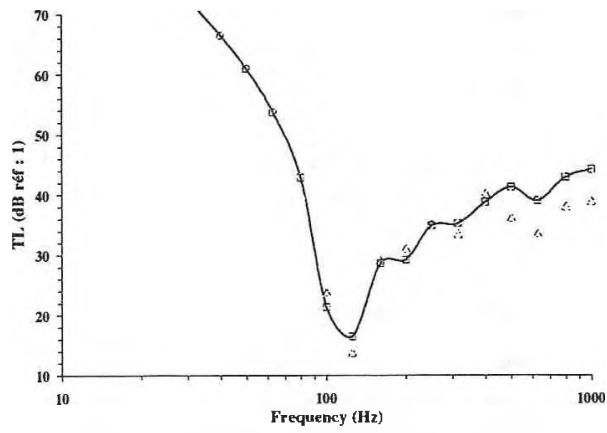

Figure 2: Transmission loss of the double plate system coupled with a $50 \mathrm{~mm}$ cavity filled with air. Numerical ? ) and experimental (?)

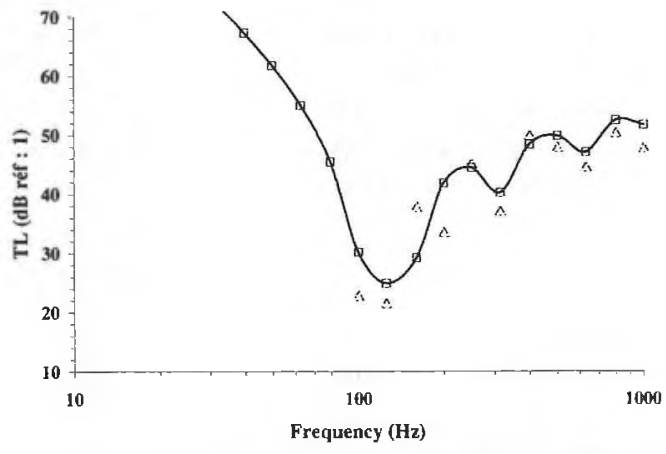

Figure 3 : Transmission loss of the double plate system coupled with a $50 \mathrm{~mm}$ cavity filled with a porous material. Numerical (?) and experimental (? )

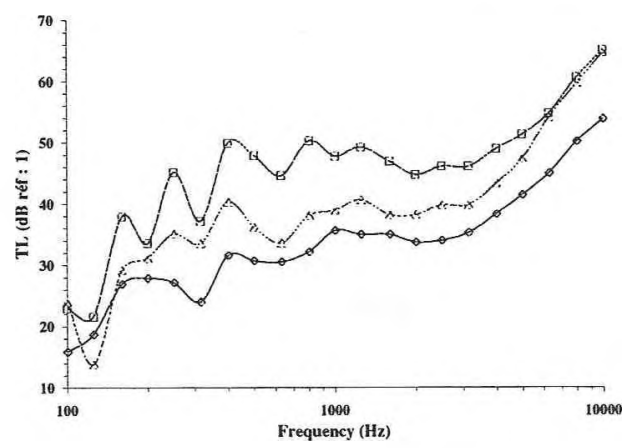

Figure 4 : Experimental results in the entire bandwidth. Simple plate $\left({ }^{?}\right)$, the double plate with air $\left({ }^{?}\right)$ and the double plate with the equivalent fluid ? ) 